\title{
Expert Witness Training for Geriatric Medicine Fellows Using Courtroom Simulation
}

\author{
Kevin T. Foley, MD | Michael J. Ferency, JD | Erin M. Sarzynski, MD, MS \\ Published: 8/8/2017| DOI: 10.22454/PRiMER.2017.468087
}

\section{Abstract}

Introduction: Familiarity with courtroom proceedings is essential for physicians before their first appearance as expert witnesses. Geriatricians who care for vulnerable older adults may be called to testify in guardianship hearings and cases involving elder abuse and contested wills. Coverage of this topic is limited in the medical literature. To enhance this knowledge, the Division of Geriatrics at Michigan State University piloted an expert witness training curriculum for its geriatric medicine fellows.

Methods: An attorney began the training with a didactic lecture to introduce principles of the trial process, evidence, records management, witness testimony, and court procedures. One week later, fellows participated in a mock trial to apply what they learned and gain experience in providing testimony. The simulated cases involved actual patients of the fellows, who were the subjects of a hypothetical contested guardianship matter. A mixed methods approach was used to assess knowledge acquisition, training effectiveness and perceived impact using a pre/post-test and an individualized, semistructured debriefing session.

Results: Two fellows participated in the training. Courtroom knowledge as assessed by the pre- and post-tests and qualitative measures improved from baseline. The fellows assessed the mock trial as a valuable experience and both felt more informed and prepared for future service as witnesses.

Conclusions: This pilot study provided geriatric medicine fellows with instruction in courtroom testimony followed by participation in a simulated trial. Fellows rated the experience highly and demonstrated measurable improvement in their knowledge of legal proceedings involving older adults and their role as expert witnesses.

\section{Introduction}

The medical profession has an ethical duty to assist patients, their families, and society with resolving disputes. ${ }^{1}$ When contested matters require judicial review, expert testimony by physicians may be essential for a court to fully and accurately understand a patient's condition, treatment, and prognosis. ${ }^{2-4}$ Without the participation of physicians in legal proceedings, the mechanisms for dispute resolution may be unsuccessful and patients may suffer. ${ }^{2-4}$ Accordingly, the opinions provided by medical experts in legal proceedings can be invaluable to guide decisions that protect patients' rights and their best interests.

Geriatricians may volunteer or be subpoenaed to offer clinical opinions as expert witnesses in court cases involving guardianship, contested wills, and elder abuse. To best assist the court with adjudicating cases, it is essential that physicians who serve as expert witnesses be familiar with courtroom proceedings, prior to their first appearance. ${ }^{5}$

Foundational and experiential education in witness testimony and court proceedings has been developed for various health professions, most notably psychiatry, pediatrics, and nursing. ${ }^{6-8}$ Geriatricians, however, infrequently receive 
formal expert witness training prior to their first courtroom appearance as this content is not a graduate medical education (GME) requirement for fellowship program accreditation, and is difficult to integrate into an intensive, 1-year postgraduate educational curriculum. Unsurprisingly, anecdotal reports from practicing geriatricians indicate their initial experiences in providing testimony are highly stressful and intimidating. The medical literature provides few resources and little guidance on the roles and responsibilities of expert witnesses beyond forensic and malpractice cases. ${ }^{9-11}$

In recognizing the considerable value of expert witness testimony and the sizable knowledge and skill gap among our trainees, a pilot educational experience was developed by the Division of Geriatric Medicine at Michigan State University (MSU) to provide theoretical and practical expert witness training for geriatric medicine fellows.

\section{Methods}

\section{Analysis}

An interdisciplinary curriculum was piloted in 2014 for two first-year geriatric medicine fellows who had no previous courtroom experience or similar training during their residencies. A review of available web-based resources failed to identify an inclusive training curriculum suitable for geriatric medicine fellows. Both indicated they were enthusiastic to participate, lacked knowledge about testifying in court, and recognized a professional benefit in gaining familiarity with legal proceedings involving older adults. Two curricular goals were developed from the gap analysis: 1) preview judicial procedures and the roles and responsibilities of expert witnesses and; 2) replicate the experience of witness testimony during a simulated court hearing.

A law professor at MSU collaborated with our faculty to codevelop and teach the curriculum, and to arrange access to a simulation courtroom used by law students. The MSU Institutional Review Board approved this project and deemed it exempt from full review. Both fellows provided written consent for their participation.

\section{Design}

To fill the curricular gap, two of the authors (KF and MF) modified an existing didactic presentation on expert testimony given to law students. A didactic session was used to introduce fundamental knowledge deemed essential by the law professor for medical expert witnesses to comprehend when providing service in both civil and criminal cases. A live, interactive teaching approach was selected to allow fellows the opportunity to ask questions and clarify their understanding of key concepts defined below. To apply new knowledge, the authors organized a mock trial to provide experience in giving expert testimony. Due to the small number of learners, a mixed methods approach was chosen to assess training effectiveness and perceived impact using a knowledge pre/post-test and an individualized, semistructured debriefing.

\section{Development and Implementation}

The law professor began the didactic session using PowerPoint slides to introduce principles of the trial process including: evidence handling, records management, witness testimony, and court procedures. ${ }^{12}$ To reinforce key points, he used anecdotes from his own cases. The training was completed in one afternoon (4 hours) and was scheduled as a single session to resolve scheduling conflicts. One week later, the fellows participated as expert witnesses in a mock trial conducted in the MSU College of Law's simulation courtroom to gain real-world experience in providing testimony. The simulated cases involved fellows' actual patients, each with diagnoses of dementia, who were subjects of a hypothetical contested guardianship matter where decisional capacity was at issue. Patients' medical records were de-identified prior to use in the mock trial. Specific elements of testimony role-played during the mock trial included courtroom etiquette, review of the curriculum vitae to verify scope of training and experience, synopsis of involvement with the case, examination and authentication of medical records, summary of clinical contacts with their patient, review of admitted evidence, and disclosure of opinion and suggested remedy. Each fellow provided their testimony to the law professor by direct examination for 1 hour while seated in the witness stand. Time and cost constraints precluded involvement of a simulated judge and a second attorney to conduct witness cross-examination. No fees were charged for the law professor's participation or use of the simulation 
courtroom.

\section{Evaluation}

Knowledge acquisition was measured using a 10-item, essay type pre-test/post-test written by the law professor and administered immediately before and after the didactic lecture, prior to the mock trial (see reference for test items uploaded in the STFM Resource Library). ${ }^{12}$ The essay format was used to lessen the likelihood of chance guessing for correct answers. Responses were graded by the law professor to evaluate the fellows' understanding of scientific method and the law, bases and handling of civil and criminal complaints by the court, types of evidence, standards used to admit expert testimony, rules of evidence, and obligations of expert witnesses. Fellows' impressions of the courtroom simulation training were assessed through an individualized, semistructured debriefing session using the Gibbs' reflective cycle. ${ }^{13}$

\section{Results}

Two fellows attended the lecture and participated in the mock trial. Fellows' courtroom knowledge markedly improved following the conclusion of the didactic session (mean pretest $3 \%$ vs post-test $98 \%$ correct). During debriefing, fellows assessed the mock trial as a valuable experience, and both indicated they felt more informed and better prepared for future service as witnesses. Both fellows found it difficult to answer hypothetical questions when limited to "yes" and "no" responses. Selected quotes recorded during the debriefing of their feelings, evaluation, and action plan included:

"Verifying my credentials took longer than I expected."

"I felt like I was being led by the attorney."

"It seemed that attorney twisted the facts to fit his strategy."

"I feel more confident answering questions in the courtroom."

"I feel better prepared to act as an expert witness."

"I will feel less scared if I ever have to go to court."

"Recommend this training for all future fellows."

Similarly, faculty felt the training was worthwhile and accurately portrayed the apprehension and perceived vulnerability experienced upon receiving their first subpoena.

\section{Discussion}

This pilot study found structured expert witness training followed by participation in a simulated trial was rated highly by geriatric medicine fellows and led to improvement in their knowledge of legal proceedings involving older adults and possible roles as expert witnesses. More importantly, the fellows gained confidence and stated they will likely feel less frightened during a first court appearance.

Several limitations of this study are noteworthy. First, the relevance of the knowledge improvement measures is uncertain given that only two fellows participated in the training during a single academic year. A longer-term single site or multisite investigation would be necessary to verify whether the qualitative and quantitative results are reproducible and valid. Second, continuing the training at our institution during subsequent years has been difficult due to inconsistent fellowship enrollment, and because the law professor who participated has since retired. Identifying a replacement for him is problematic due to our inability to pay for an attorney's time (hourly rate at most). Institutions wanting to replicate this training for their geriatric medicine fellows could be equally challenged in securing funding outside of the GME budget to cover costs. Finally, our mock trial was conducted in an empty courtroom with one attorney. Although the primary goals of our pilot training were achieved, the simulated trial was 
truncated and imperfectly reproduced a true courtroom atmosphere. Securing a real courtroom, a second attorney to perform cross-examination, a mock jury, and a judge to more realistically replicate the experience of testifying could make the activity more authentic and effective. ${ }^{6}$ Given the benefits realized, we are continuing to seek funding to continue this training for our future fellows, as recommended by the participants. Feedback from our fellows, should they ever provide courtroom testimony, would be invaluable to determine what additional didactic and simulation elements should be considered in future trainings to improve the quality of the experience.

\section{Conclusion}

The expert witness curriculum resulted in measurable subjective and objective improvements in geriatric medicine fellows' knowledge of legal proceedings and raised self confidence in their role as expert witnesses using a novel type of interprofessional education involving an attorney. Moreover, the mock trial experience provides an additional, unique means to assess fellows in the core competency of professionalism using courtroom simulation. Further study of physician expert witness training in graduate medical education programs is warranted.

\section{Acknowledgements}

\section{Prior Presentations of Manuscript Content:}

Peer Reviewed Poster: American Geriatrics Society 2015 Annual Meeting, National Harbor, Maryland, May 2015.

Peer Reviewed Presentation: American Geriatrics Society 2015 Annual Meeting, Teachers Section Materials and Methods Swap, National Harbor, Maryland, May 2015.

\section{Corresponding Author}

Kevin T. Foley, MD

College of Human Medicine, Department of Family Medicine, Division of Geriatrics Michigan State University 788 Service Road, Room B110 Clinical Center, East Lansing, MI 48824. Tel (517) 884-0446. Fax (517) 355-7700

Kevin.foley@hc.msu.edu

\section{Author Affiliations}

Kevin T. Foley, MD - College of Human Medicine, Department of Family Medicine, Division of Geriatrics, Michigan State University

Michael J. Ferency, JD - Michigan State University College of Law

Erin M. Sarzynski, MD, MS - College of Human Medicine, Department of Family Medicine, Division of Geriatrics, Michigan State University

\section{References}

1. Snyder L. Guidelines for the physician expert witness. Ann Intern Med. 1990 Nov 15;113(10):789. https://doi.org/10.7326/0003-4819-113-10-789.

2. Fallat ME, Glover J. Professionalism in pediatrics. Pediatrics. 2007 Oct;120(4):e1123-e1133. https://doi.org/10.1542/peds.2007-2230

3. Snyder L. American College of Physicians Ethics Manual: Sixth Edition. Ann Intern Med. 2012 Jan 3;156(1_Part_2):73-104. https://doi.org/10.7326/0003-4819-156-1-201201031-00001.

4. Cheshire WP, Hutchins JC. Professionalism in court: the neurologist as expert witness. Neurol Clin Pract. 2014;4(4):335-341. https://doi.org/10.1212/CPJ.0000000000000041.

5. Hartigan-Go K. Presenting evidence for the court. Int J Risk Saf Med. 2012;24:59-63. https://doi.org/10.3233/JRS-2012-0554.

6. Glancy GD. The mock trial: revisiting a valuable training strategy. J Am Acad. Psychiatry Law. 2016 
Mar;44(1):19-27.

7. Committee on Medical Liability and Risk Management. Expert witness participation in civil and criminal proceedings. Pediatrics. 2009 Jul;124(1):428-438.

https://doi.org/10.1542/peds.2009-1132.

8. March AL, Ford CD, Adams MH, et al. The mock trial: a collaborative interdisciplinary approach to understanding legal and ethical issues. Nurse Educ. 2011 Mar-Apr;36(2): 66-69. https://doi.org/10.1097/NNE.0b013e31820b5029.

9. Drukteinis DA, O'Keefe K, Sanson T, Orban D. Preparing emergency physicians for malpractice litigation: a joint emergency medicine residency-law school mock trial competition. J Emerg Med. 2014 Jan;46(1):95-103 https://doi.org/10.1016/j.jemermed.2013.08.017

10. Hochberg MS, Seib CD, Bernam RS et al. Perspective: Malpractice in an acedmic medical center: a frequently overlooked aspect of professionalism education. Acad Med 2011 Mar;86(3):365-8. doi: 10.1097/ACM.0b013e3182086d72. https://doi.org/10.1097/ACM.0b013e3182086d72

11. Gutheil T. The Psychiatrist in Court: A Survival Guide. Washington, DC: American Psychiatric Press; 1998.

12. Foley K, Ferency M. Michigan State University expert witness training curriculum for geriatric medicine fellows (PPT and Word documents). STFM Resource Library. https://resourcelibrary.stfm.org/viewdocument /sparrow-msu-geriatrics-fellowship-e?CommunityKey=2751b51d-483f-45e2-81de-4faced0a290a\& tab=librarydocuments Published January, 2017. Accessed July 2017.

13. Gibbs G. Learning by Doing: A Guide to Teaching and Learning Methods. Oxford, UK: Oxford Polytechnic; 1988.

Copyright $@ 2017$ by the Society of Teachers of Family Medicine 